sputum and the genesis of adult chronic obstructive lung disease are complex. A steeper rate of decline in forced expiratory volume in one second has been shown in those smokers with a history of childhood respiratory symptoms or evidence of bronchoreactivity. ${ }^{81112}$ The subjects in this study may be at increased risk of developing chronic obstructive lung disease because of their asthma and smoking habits. Subjects in grade W may not be risk free, as $60 \%$ of them continued to show bronchial hyperreactivity though many had been wheeze free for 10 years or more. ${ }^{16}$

This study emphasises the need for better education of children and teenagers with asthma in the hope that as young adults they will seek more appropriate medical care and so reduce the morbidity from their disease. Further, education may reduce the incidence of smoking and hopefully thereby reduce the possible risk of their developing chronic obstructive lung disease in later life.

This study was supported by grants from the National Health and Medical Research Council and the Asthma Foundation of Victoria.

\section{References}

1 McNicol KN, Williams HE. Spectrum of asthma in children-I, clinical and physiological components. $\mathrm{Br}$ Med $\mathcal{F} 1973$;iv:7-11.

2 Speight ANP. Is childhood asthma being underdiagnosed and undertreated ? $\mathrm{Br}$ Med $\mathcal{F} 1978$;ii:331-2.

${ }^{3}$ Flensborg EW. The prognosis of bronchial asthma arising in infancy after the nonspecific treatment hitherto applied. Acta Paediatr Scand 1945; $33: 4-23$.

- Peckham C, Butler N. A national study of asthma in childhood. $\mathcal{F}$ Epidemiol Community Health 1978;32:79-85.

${ }^{5}$ Mitchell RG, Dawson B. Educational and social characteristics of children with asthma. Arch Dis Child 1973;48:467-71.

${ }^{6}$ Graham PJ, Rutter ML, Yule W, Pless IB. Childhood asthma: a psychosomatic disorder? Some epidemiological considerations. British fournal of Preventive Medicine 1967;21:78-85.

' Rawls DJ, Rawls JR, Harrison CW. An investigation of six to eleven yearold children with allergic disorders. F Consult Clin Psychol 1971 ;36:260-4.

${ }^{8}$ Burrows B, Lebowitz MD, Knudson RJ. Epidemiologic evidence that childhood problems predispose to airways disease in the adult (an asso- $\underline{\underline{\sigma}}$ ciation between adult and paediatric respiratory disorders). Pediatr Res $1977 ; 11: 218-20$.

${ }^{9}$ Holland WW, Halil T, Bennett AE, Elliott A. Factors influencing the onset of chronic respiratory disease. Br Med $\mathcal{F} 1969$;ii:205-8.

${ }^{10}$ Colley JRT, Douglas JWB, Reid DD. Respiratory disease in young adults: $\widehat{\Omega}$ influences of early childhood, lower respiratory tract illness, social class, air pollution, and smoking. Br Med f 1973;iii:195-8.

$"$ Barter CE, Campbell AH, Tandon MK. Factors affecting the decline in $\mathrm{FEV}_{1}$ in chronic bronchitis. Aust NZ F Med 1974;4:339-45.

12 Barter CE, Campbell AH. Relationship of constitutional factors and $\prod_{0}$ cigarette smoking to decrease in 1-second forced expiratory volume. $\mathrm{Am}$.. Rev Respir Dis 1976;113:305-14.

13 Williams HE, McNicol KN. Prevalence, natural history and relationship $\stackrel{\vec{\sim}}{+}$ of wheezy bronchitis and asthma in children. An epidemiological study. Br Med F 1969 ;iv:321-5.

14 Martin AJ, McLennan L, Landau LI, Phelan PD. The natural history of $\frac{\bar{\sigma}}{\overline{\mathrm{D}}}$ childhood asthma to adult life. $B r$ Med f 1980;280:1397-400.

15 Silverman M, Anderson SD. Standardisation of exercise tests in asthmatic $\stackrel{\mathbb{Q}}{\mathbb{Q}}$ children. Arch Dis Child 1972;47:882-9.

16 Martin AJ, Landau LI, Phelan PD. Lung function in young adults who ڤึ had asthma in childhood. Am Rev Respir Dis 1980;122:609-16.

17 Medical Research Council Committee on the Aetiology of Chronic Bronchitis. Definition and classification of chronic bronchitis for clinical $\overrightarrow{\vec{\omega}}$ and epidemiological purposes. Lancet 1965; ; :775-9.

${ }^{18}$ Simpson WT. Initial studies on the human pharmacology of salbutamol. Postgrad Med F 1971;47, suppl:35-8.

19 McNicol KN, Williams HE, Allan J, McAndrew I. Spectrum of asthma in children-III, psychological and social components. Br Med $\mathcal{F} 1973 ; \underset{\perp}{\infty}$ iv : $16-20$.

20 Bieman CW, Kawabori I, Pierson WE. Incidence of exercise induced $\omega$ asthma in children. Pediatrics $1975 ; 56$, suppl:847-50.

21 Woolcock AJ, Leeder SR, Peat JK, Blackburn SRB. The influence of lower $\omega$ respiratory illness in infancy and childhood and subsequent cigarette $\mathscr{N}$ smoking on lung function in Sydney school children. Am Rev Respir Dis $1979 ; 120: 5-14$

22 Kuperman AS, Riker JB. The variable effect of smoking on pulmonary or function. Chest 1973;63:655-60.

${ }^{23}$ Burrows B, Knudson RJ, Cline MG, Lebowitz MD. Quantitative re- $\frac{\mathbb{D}}{O}$ lationships between cigarette smoking and ventilatory function. Am Rev Respir Dis 1977;115:195-205.

24 Sanerkin NG. Terminology and classification of 'bronchial asthma' and 'chronic bronchitis': a reappraisal and redefinition. Ann Allergy 1971; $\vec{\bullet}$ 29:187-93.

\title{
Rubella screening and immunisation of schoolgirls: results six to seven years after vaccination
}

\author{
HELEN ZEALLEY， ELIZABETH EDMOND
}

\begin{abstract}
A long-term follow-up study was carried out of girls given RA27/3 or Cendehill rubella vaccine in their 13th14th year compared with a group of girls who had been found to be naturally immune at that age. $A$ high proportion of the girls in all groups had persistent rubella antibody six to seven years after inclusion in the study, although some of these would have been considered to be susceptible to rubella by methods currently in use for screening for rubella antibody.

Great care should be taken in interpreting the efficiency of the schoolgirl immunisation policy in the United Kingdom; women in their childbearing years who may
\end{abstract}

\section{Lothian Health Board}

HELEN ZEALLEY, MD, FFCM, community medicine specialist

Bacteriology Department, University of Edinburgh, and Regional

Virus Laboratory, City Hospital, Edinburgh

ELIZABETH EDMOND, MB, FRCPATH, senior lecturer have received vaccine but are found by a screening test $\frac{\delta}{2}$ to be seronegative should be retested by a more sensitive procedure before a final report is made.

\section{Introduction}

The aim of rubella vaccination policies in most European countries is to ensure that all women of childbearing age are $\omega$ immune to rubella. In practice this usually results in the offer of vaccine to all girls between their 11 th and 14th birthdays in $\stackrel{0}{=}$ Britain. To be effective in reducing the incidence of congenital $\stackrel{\Phi}{\oplus}$ rubella vaccine-induced immunity must persist throughout the reproductive period. We report here the results of a follow-up 0 study of immunity in schoolgirls who had been vaccinated and $\stackrel{\mathbb{D}}{\mathbb{D}}$ controls.

\section{Study group and procedure}

An immunisation programme aimed at Edinburgh schoolgirls in their 13-14th years was reported in $1974 . .^{1}$ All girls were screened for 
haemagglutination inhibition (HAI) antibody and those with titres of $<32$ were offered immunisation with RA27/3 or Cendehill strains of rubella vaccine.

From the original cohort recruited to the programme in 1970, 537 initially seronegative girls were paired as far as possible with seropositive control girls who had been found to have HAI antibody titres of .32 from natural infection. Of those who were initially seronegative, 520 accepted the offer of rubella vaccine while 17 chose to remain as seronegative controls. A total of 1072 girls in these groups were enrolled in a follow-up study to compare their rubella antibody titres during their childbearing years. The results of the first antibody tests after one year in the study have already been reported. ${ }^{1}$ Of 1031 girls tested at the end of the first year of study, $958\left(93^{\circ} \circ\right)$ had HAI antibody titres the same as or within a twofold variation of the titre found in a serum sample taken two months after vaccination

Annual contact with the girls was maintained by sending a returnable questionnaire enclosed with a birthday card. Up to four reminders were sent to those who did not respond immediately, and, when necessary, attempts were made by contacts with parents, neighbours, general practitioners, and the local health board listing to trace girls who failed to respond or had moved house.

During the sixth and seventh years of the study sera were collected from those who could attend evening sessions in a central Edinburgh clinic. In addition, specimens from some subjects who had moved out of Edinburgh were posted to the laboratory by general practitioners. These sera were tested initially for rubella antibodies by a HAI test in parallel with the specimens that had been stored at $-20^{\circ} \mathrm{C}$ since collection one year after enrolment in the study.

Laboratory methods-Details of the HAI test were as reported previously. ${ }^{1}$ Paired sera showing a fourfold or greater rise or fall in antibody in the HAI test were retested; only confirmed changes in titre were recorded. All sera that consistently gave HAI antibody titres of 16 or less were referred for testing by radioimmunoassay to the laboratory at St Thomas's Hospital Medical School, London. ${ }^{2}$ As many sera as possible were also tested by a single radial haemolysis test. $^{3}$ All tests were read by eye. Subjects whose sera produced zones of haemolysis greater or equal to that produced by a standard serum (Standards Laboratory, Colindale) were considered to be immune.

\section{Results}

Specimens were obtained six to seven years after vaccination from $816(76 \%)$ of the 1072 girls originally enrolled in the study. The overall response from the girls who had received vaccine $(84 \%)$ was greater than that from either the naturally seropositive controls $(70 \%)$ or the much smaller group of seronegative controls $(41 \%)$ who had refused vaccine when they were initially found to be seronegative and who had never shown much interest in the study.

Table I shows the results of the HAI tests on paired sera from the girls in each category. Sera were classed as those that would be accepted as containing rubella antibody (HAI $>32)$ and those clearly without antibody (HAI <16). Sera with titres of only 16 were grouped together as low-titre sera that might or might not have contained virusspecific antibody. The proportion of follow-up sera with HAI

TABLE I-HAI antibody titres six to seven years after enrolment in study

\begin{tabular}{|c|c|c|c|c|}
\hline \multirow{3}{*}{$\begin{array}{l}\text { Results of HAI } \\
\text { tests on paired } \\
\text { sera taken at } \\
\text { one year and } \\
\text { six to seven } \\
\text { years after } \\
\text { enrolment in } \\
\text { study }\end{array}$} & \multicolumn{4}{|c|}{ Results of original screening test and vaccine category } \\
\hline & \multirow{2}{*}{$\begin{array}{c}\text { Titre } \\
\geqslant 32 \\
(n=374)\end{array}$} & \multicolumn{3}{|c|}{ Titre $\cdot 32$} \\
\hline & & $\begin{array}{l}\text { RA } 27 / 3 \text { vaccine } \\
\left(n=251^{*}\right)\end{array}$ & $\begin{array}{l}\text { Cendehill vaccine } \\
\qquad(\mathrm{n}=184)\end{array}$ & $\begin{array}{l}\text { No vaccine given } \\
\qquad(\mathrm{n}=7)\end{array}$ \\
\hline $\begin{array}{l}\text { Stable titre: } \\
\text { Good }(\geqslant 32) \\
\text { Low }(16) \\
<16\end{array}$ & $\begin{array}{c}343(91 \cdot 7) \\
14(3 \cdot 7)\end{array}$ & $\begin{aligned} 190 & (75 \cdot 7) \\
31 & (12 \cdot 4) \\
3 & (1 \cdot 2)\end{aligned}$ & $\begin{array}{r}130(70 \cdot 7) \\
19(10 \cdot 3) \\
2(1 \cdot 1)\end{array}$ & $\begin{array}{l}1(14 \cdot 3) \\
4(57 \cdot 1)\end{array}$ \\
\hline $\begin{array}{l}\text { Fourfold or grea } \\
\text { From } \geqslant 32 \\
\text { From } 16 \\
\text { From }<16\end{array}$ & $\begin{array}{l}\text { ater rise in a } \\
\quad 1(0.3)\end{array}$ & ntibody titre: & $\begin{array}{l}5(2 \cdot 7) \\
1(0 \cdot 5)\end{array}$ & $2(28 \cdot 6)$ \\
\hline $\begin{array}{l}\text { Fourfold or grea } \\
\text { To } \geqslant 32 \\
\text { To } 16 \\
\text { To } 16\end{array}$ & $\begin{array}{c}\text { ater fall in a } \\
6(1 \cdot 6) \\
3(0 \cdot 8) \\
7(1.9)\end{array}$ & $\begin{array}{r}\text { ntibody titre: } \\
8(3 \cdot 2) \\
4(1 \cdot 6) \\
15(6 \cdot 0)\end{array}$ & $\begin{array}{r}6(3 \cdot 3) \\
5(2 \cdot 7) \\
16(8 \cdot 7)\end{array}$ & \\
\hline
\end{tabular}

- One specimen not suitable for HAI testing. antibody titres of $\geqslant 32$ was significantly greater in the naturally immune group $(93.6 \%)$ than in either the group given RA27/3 vaccine $(78.9 \%)$ or the group given Cendehill vaccine $(76.5 \%)$ (Cendehill vaccine: $\chi^{2}=31 \cdot 8, \mathrm{df}=1, \mathrm{p}<0.001 ; \mathrm{RA} 27 / 3$ vaccine: $\chi^{2}=30 \cdot 0, \mathrm{df}=1$, $\mathrm{p}<0.001)$. No difference was found between the two groups given the vaccine. Conversely, the proportion of follow-up sera with stable low HAI antibody titres of 16 among these two groups was significantly higher than that among the group who had initially been naturally immune (considering the vaccine groups together $\chi^{2}=19 \cdot 2, \mathrm{df}=1$, $\mathrm{p}<0.001$ )

Stable titres of less than 16 were found in three subjects $(1.2 \%)$ given RA27/3 vaccines, two $(1 \cdot 1 \%)$ given Cendehill vaccine, and four $(57 \%)$ seronegative controls but in none of the naturally seropositive controls. Tests on four of these five subjects in whom the vaccine failed had been consistently seronegative after vaccination (with RA27/3 in two and Cendehill in two), but serum from the third subject given RA27/3 vaccine had shown a titre of 32 one year after immunisation. In addition to those whose sera showed persistent HAI antibody titres below 16 , a further seven $(1.9 \%)$ of the naturally immune girls, $15(6.0 \%)$ of those given RA27/3 vaccine, and $16(8.7 \%)$ of those given Cendehill vaccine had HAI antibody titres that had fallen to less than 16 between the tests done at one year and at six to seven years.

A total of $53(21 \cdot 1 \%)$ follow-up sera obtained from subjects given RA27/3 vaccine and $43(23.4 \%)$ obtained from those given Cendehill vaccine were considered to be negative or doubtful for rubella antibody by the HAI test alone. Again no significant difference was found between the two groups given the vaccines $\left(\chi^{2}=0 \cdot 182, \mathrm{df}=1, \mathrm{p}<0 \cdot 5\right)$. A routine screening programme based on the HAI test, which is still used in some laboratories, would therefore indicate that up to $23 \%$ of those who had been given rubella vaccine had no immunity or only doubtful immunity to rubella at the end of six or seven years.

Since the laboratory minimum immune titre for HAI testing must take into account the possibility of inhibition by non-specific inhibitors it would be expected that in some sera considered to be non-immune by the HAI test antibody would be confidently detected by tests in which this problem does not occur. Table II shows the much smaller number of follow-up sera considered to be negative when tested by the single radial haemolysis test, which is now used by most laboratories as the standard test for screening for rubella antibody.

TABLE II-Results of single radial haemolysis used on followup sera obtained after six to seven years

\begin{tabular}{llc}
\hline Original group & No tested & $\begin{array}{c}\text { No (\%) negative } \\
\text { by single radial } \\
\text { haemolysis }\end{array}$ \\
\hline Naturally immune & 371 & $5(1 \cdot 3)$ \\
Vaccinated with: & 248 \\
$\begin{array}{c}\text { RA27/3 } \\
\text { Cendehill }\end{array}$ & $\begin{array}{r}7(2 \cdot 8) \\
\text { Seronegative controls }\end{array}$ & 7
\end{tabular}$\quad \begin{gathered}\begin{array}{r}7(7 \cdot 6) \\
4(57 \cdot 1)\end{array} \\
\end{gathered}$

We investigated the poorly reacting sera further. Second sera with HAI antibody titres of $\leqslant 16$ were tested by radioimmunoassay by Professor Banatvala at St Thomas's Hospital. Subjects whose sera had HAI antibody titres of 16 but titres of $>160$ by radioimmunoassay were considered to be immune since previous studies have shown that when such people are challenged they either show little or no booster antibody response or develop a typical secondary immune response. Table III shows the results of radioimmunoassay of the follow-up sera that had HAI antibody titres of $<16$ (not all such sera were available for testing). The last column in table III gives the proportion of sera in each group that would probably have been regarded as seronegative

TABLE III-Results of radioimmunoassay in subjects with $H A I$ antibody titre $<16$

\begin{tabular}{|c|c|c|c|}
\hline Original group & $\begin{array}{c}\text { No tested by } \\
\text { radioimmunoassay/ } \\
\text { total No with HAI } \\
\text { antibody titre }<16\end{array}$ & $\begin{array}{c}\text { No negative/ } \\
\text { No tested by } \\
\text { radioimmunoassay } \\
\left(0_{0}\right)\end{array}$ & $\begin{array}{l}\% \text { of total No of } \\
\text { follow-up sera } \\
\text { probably negative } \\
\text { by } \\
\text { radioimmunoassay }\end{array}$ \\
\hline $\begin{array}{l}\text { Naturally immune } \\
\text { Vaccinated with: }\end{array}$ & $5 / 6$ & $2 / 5(40 \cdot 0)$ & 0.6 \\
\hline $\begin{array}{l}\text { RA27/3 } \\
\text { Cendehill }\end{array}$ & $\begin{array}{l}17 / 18 \\
13 / 18\end{array}$ & $\begin{array}{l}4 / 17(23 \cdot 5) \\
6 / 13(46 \cdot 2)\end{array}$ & $\left.\begin{array}{l}1 \cdot 05 \\
4 \cdot 1\end{array}\right\} 2 \cdot 2$ \\
\hline $\begin{array}{l}\text { Seronegative } \\
\text { controls }\end{array}$ & $3 / 4$ & $3 / 3(100)$ & $57 \cdot 0$ \\
\hline
\end{tabular}


if radioimmunoassay had been used throughout. The radioimmunoassay clearly identified a much smaller proportion of test sera in all groups as being totally devoid of rubella antibody, while still reliably assaying the seronegative controls.

\section{Discussion}

The most recently available results of long-term follow-up of subjects given rubella vaccine indicate that detectable HAI antibody may persist for 10 years after vaccination with RA27/3 vaccine $^{5}$ and for nine years after vaccination with Cendehill vaccine. ${ }^{6}$ Schiff et al, ${ }^{7}$ however, found $23(6.6 \%)$ out of 346 subjects given Cendehill vaccine to be without HAI antibody after seven and a half years. Our results confirm that in over $90 \%$ of subjects given rubella vaccine detectable HAI antibody persists six to seven years after vaccination. In $14.0 \%$ of the subjects given RA27/3 vaccine and $13.0 \%$ of the subjects given Cendehill vaccine, however, the HAI antibody titres fell below the minimum immune titre of 32 , which would have been considered to represent doubtful immunity if the sera had been routinely tested (for example, from an antenatal clinic). In addition, of those who had been naturally immune at the start of the study, $1.9 \%$ were found not to be immune and $4.5 \%$ to have doubtful immunity six to seven years later. These are significantly smaller proportions than those found in subjects who had been vaccinated, but our results confirm a previous report ${ }^{8}$ that loss of naturally acquired rubella immunity is a rare but recognised event.

When this prospective study was started in 1969 the laboratory minimum immune titre for the HAI test was 32 , to allow for the difficulty of interpreting low-titre sera (titre of 16 or less) that may have contained specific antibody or non-specific inhibitor. With more experience of the HAI test and in particular with the better standardisation of the test after acceptance of the concept of a minimum immune titre based on international units $^{9}$ it was apparent that the vast majority of sera giving titres of 16 in our laboratory contained specific antibody: this was confirmed by testing with more sensitive techniques. Single radial haemolysis indicated that $97.2 \%$ of subjects given $\mathrm{RA} 27 / 3$ vaccine and $92.4 \%$ of subjects given Cendehill vaccine were still immune to rubella after six to seven years. Correlation between negative findings with single radial haemolysis and the HAI antibody titre was good but not absolute (paper in preparation). In addition, we found specific rubella antibody by radioimmunoassay in some sera with HAI antibody titres of $<16$. Until recently the HAI test was used routinely in many laboratories screening sera from adult women, and concern has been expressed ${ }^{10}$ at the high number of negative and doubtful reports received from patients who were known to have been vaccinated.

Screening of schoolgirls before immunisation is not a routine procedure, and most girls will have received vaccine between their 11th and 14th birthdays without their serological status to rubella being known. Results of previous studies ${ }^{1}$ suggest that about $70 \%$ will already have acquired natural immunity by that age. Extrapolation of our results in subjects who had been vaccinated will therefore apply only to the remaining $30 \%$ of the total population of immunised women entering the childbearing period. Thus, with about $22 \cdot 1 \%$ of vaccinated subjects $(21 \cdot 1 \%$ of those given RA27/3 vaccine and $23.4 \%$ of those given Cendehill vaccine) showing little or no apparent HAI antibody six to seven years after immunisation $6.3 \%(22 \cdot 1 \%$ of $30 \%)$ of the total population in this age group would appear to be nonimmune or give borderline HAI antibody titres.

Although a much smaller loss of apparent immunity (6.4\%) was detected in those who had acquired natural immunity in childhood, this group also contributes to those who are apparently unprotected because they represent a much larger proportion $(70 \%)$ of the schoolgirl population who routinely $\underline{\underline{T}}$ receive vaccine: the contribution is $4.5 \%(6.4 \% \times 70 \%)$ to the 3 total population entering their main childbearing period. Thus, $\stackrel{\AA}{\circ}$ using the relatively insensitive HAI screening test, almost $11 \% 乞$ of women of childbearing age would appear to require rubella $\widehat{\widehat{O}}$ vaccine even if there has been $100 \%$ uptake of rubella vaccine at school.

Similar extrapolation from the more sensitive single radial ${ }^{\infty}$ haemolysis test, however, indicates that only $2.4 \%$ of a total immunised childbearing population would be identified as seronegative and requiring vaccination $(1.3 \%$ of $70 \%$ plus $4.9 \% \stackrel{\rho}{\stackrel{\rho}{9}}$ of $30 \%$ ), while radioimmunoassay would reduce the figure to $1.4 \%(0.6 \%$ of $70 \%$ plus $2 \cdot 2 \%$ of $30 \%)$.

The above figures assume $100 \%$ uptake of vaccine. Any definitive evaluation of the schoolgirl programme must also take $\mathbb{Q}$ account of the small group who have never acquired natural immunity and who for some reason have failed to be immunised by the schoolgirl programme: often this group is difficult to. identify. We therefore recommend that great care should be $\vec{\overrightarrow{ }}$ taken in interpreting the efficiency of the schoolgirl immunisa- $\omega$ tion policy, especially in relation to routine screening results, $\frac{}{3}$ which might be unreliably based on the HAI test. To reduce the risk of public loss of confidence in the vaccination programme $N_{\infty}$ women in their childbearing years who may previously have received vaccine at school, post partum, or for specific employ- $\omega$ ment and who are found by a screening test to be seronegative $\vec{\omega}$ should be retested by a more sensitive procedure before a final report is made.

These results form part of a long-term study on rubella vaccines $\frac{\mathbb{D}}{0}$ generously supported by the Scottish Home and Health Department. We thank all those participating in the study and those general practitioners who helped to collect specimens. We are grateful to Professor J E Banatvala, Dr D Freestone, and Professor J G Collee for helpful advice and encouragement.

\section{References}

${ }^{1}$ Zealley H. Rubella screening and immunisation of schoolgirls: a long term evaluation. British fournal of Preventive and Social Medicine 1974;28: 54-9.

${ }^{2}$ Harcourt GC, Best JM, Banatvala JE. Rubella-specific serum and naso- $\frac{0}{3}$ pharyngeal antibodies in volunteers with naturally acquired and vaccineinduced immunity after intranasal challenge. $\mathcal{F}$ Infect Dis 1980;142: 145-55.

${ }^{3}$ Kurtz JB, Mortimer PP, Mortimer PR, Morgan-Capner P, Shafi MS, White GB. Rubella antibody measured by radial haemolysis. Characteristics and performance of a simple screening method for use in diagnostic laboratories. $\mathcal{F}$ Hyg (Lond) 1980;84:213-22.

1 Best JM, Harcourt GC, Druce A, Palmer SJ, O'Shea S, Banatvala JE. Rubella immunity by four different techniques: results of challenge ${ }^{\circ}$ studies. F Med Virol 1980;5:239-47.

${ }^{5}$ Hillary IB, Griffith AH. Persistence of antibody 10 years after vaccination with Wistar RA27/3 strain live attenuated rubella vaccine. $\mathrm{Br} M e d \mathcal{F}$ 음 $1980 ; 280: 1580-1$.

6 Just M, Berger-Hernadez R, Burgin-Wolff AM. Serum antibody nine years after Cendehill rubella immunisation. Lancet 1977;ii:1349.

7 Schiff GM, Rauh JL, Young B, Trimble S, Rotte T, Schiff BE. Rubella-음 vaccinated students. Follow-up in a public school system. $\mathcal{F} A M A 1978 ; \mathrm{N}$ $240: 2635-7$.

${ }^{8}$ Black FL, Lamm SH, Emmons JE, Pinheiro FP. Durability of antibody N titres induced by $\mathrm{RA} 27 / 3$ rubella virus vaccine. $\mathcal{F}$ Infect Dis $1978 ; 137: \sigma$ 322-3.

9 Bradstreet PCM, Kirkwood B, Pattison JR, Tobin JO. The derivation of a minimum immune titre of rubella haemagglutination-inhibition (HI) antibody. A Public Health Laboratory Service collaborative survey. $\stackrel{\mathscr{S}}{+}$ 7 Hyg (Lond) $1978 ; 81: 383-8$.

10 Broadbent E, Ajnia N, Hurley R. Susceptibility to rubella in a pregnant population after the introduction of vaccination. $\mathcal{F}$ Clin Pathol $1980 ; 33: \frac{\vec{D}}{\mathscr{D}}$ 24-7.

(Accepted 3 November 1981)

,

